\title{
Avaliação das técnicas de imunodifusão em gel de ágar, ensaio imunoenzimático indireto e reação em cadeia da polimerase no diagnóstico da brucelose ovina
}

\author{
[Evaluation of technical, immunodiffusion agar gel, enzyme-linked immunosorbent assay and \\ polymerase chain reaction in the diagnosis of ovine brucellosis]
}

\section{L.S.A. Teixeira ${ }^{1}$, A.L.B.B. Mineiro ${ }^{2}$, J.F. Batista ${ }^{1}$, M.V. Santana ${ }^{3}$, F.F.F. Soares ${ }^{3}$, N.R.O. Paula ${ }^{2}$, D.S. Lima ${ }^{4}$, T.C.M. Damasceno ${ }^{3}$, K.P. Porfirio ${ }^{1}$, M.S.C. Lustosa ${ }^{1}$}

\author{
${ }^{1}$ Aluno de pós-graduação - Universidade Federal do Piauí - Teresina, PI \\ ${ }^{2}$ Universidade Federal do Piauí - Teresina, PI \\ ${ }^{3}$ Residente - Universidade Federal do Piaú - Teresina, PI \\ ${ }^{4}$ Médico Veterinário Autônomo
}

\begin{abstract}
RESUMO
A brucelose na espécie ovina tem recebido destaque, uma vez que se trata de uma enfermidade que acomete o sistema reprodutivo dos animais, provocando sério comprometimento no setor produtivo. Dessa forma, objetivou-se a avaliação de três métodos para o diagnóstico da brucelose ovina: o ensaio imunoenzimático indireto (ELISAi), a técnica imunodifusão em gel de ágar (IDGA) e a reação em cadeia da polimerase (PCR). Para tanto, utilizaram-se 211 amostras de sangue de ovinos oriundos de propriedades de nove municípios da microrregião homogênea de Teresina, Piauí. As 211 amostras de sangue foram submetidas aos testes sorológicos e à PCR, visando detectar anticorpos anti-B. ovis e DNA de Brucella ovis, respectivamente. Foram obtidos resultados positivos nos testes sorológicos, sendo $36(17,06 \%)$ positivos no teste IDGA e sete $(3,31 \%)$ positivos no teste ELISAi, contudo não houve resultados positivos na técnica de PCR. Dos métodos de diagnóstico utilizados neste estudo, o teste IDGA foi o que apresentou melhor desempenho na detecção de animais reagentes, quando comparado ao teste ELISAi e à PCR em amostras de sangue, e o percentual de animais soropositivos sugere uma ampla distribuição de ovinos infectados por Brucella ovis na região em estudo, o que pode causar prejuízos aos produtores.
\end{abstract}

Palavras-chave: Brucella ovis, sorologia, biologia molecular

\begin{abstract}
Brucellosis in sheep has received a major focus, since it is a disease that affects the reproductive system of animals, causing serious impairment in the productive sector. Thus, three methods for the diagnosis of ovine brucellosis were evaluated as goal, the indirect Linked Immunosorbent Assay (ELISAi) test, the Immunodiffusion Agar Gel (AGID) technique and the Polymerase Chain Reaction (PCR). Therefore, we used 211 sheep blood samples from properties of nine municipalities of the homogeneous micro-region of Teresina, Piaui. The 211 blood samples were subjected to serologic testing and PCR to detect anti-B. ovis antibodies, and Brucella ovis DNA, respectively. Positive results in serological tests were obtained, 36 (17\%) positive in the AGID test and seven (3.3\%) positive to the ELISAi test, however, there were no positive results in the PCR technique. Of the diagnostic methods used in this study, the AGID test was the one that presented the best performance in the detection of reactive animals, when compared to ELISAi and PCR in blood samples and, the percentage of seropositive animals suggests a wide distribution of Brucella ovis infected sheep in the study region and could cause loss to producers.
\end{abstract}

Keywords: Brucella ovis, serology, molecular biology

\section{INTRODUÇÃO}

A brucelose é uma enfermidade infectocontagiosa comum a várias espécies animais, como, por exemplo, a espécie ovina.
Dessa forma, a brucelose em ovinos provocada pela infecção por $B$. ovis ocasiona nesses animais problemas nos órgãos reprodutivos, como epididimites, orquites, placentites, abortamentos esporádicos, elevada frequência de nascidos

Recebido em 7 de abril de 2017

Aceito em 10 de outubro de 2017

E-mail: leticiasoateixeira@gmail.com 
vivos com baixo peso e baixa viabilidade, condicionando, assim, a morte perinatal dos cordeiros (Nozaki et al., 2011).

O gênero Brucella caracteriza-se por apresentar bactérias cuja morfologia é de cocobacilos, Gram-negativos não capsulados, imóveis e não formadores de esporos. As bactérias desse gênero são consideradas intracelulares facultativas, apresentam morfologia colonial rugosa ou lisa, como, por exemplo, a B. ovis, que apresenta colônia permanentemente rugosa (Pessegueiro et al., 2003). De acordo com Schlabritz- Loutsevitch et al. (2009), atualmente existem nove espécies nomeadas: $B$. ovis, $B$. melitensis, $B$. abortus, $B$. suis, B. canis, $B$. neotomae, B. ceti, B. pinnipedialis e B. microti.

Métodos de diagnóstico eficientes para detecção de enfermidades infectocontagiosas que acometem os animais do setor de produção, salientando-se a ovinocultura de corte, têm sido cada vez mais necessários, devido ao significativo crescimento da ovinocultura e à demanda comercial do exterior, que requer adequada regularização do estado sanitário dos animais (Marques, 2006). Assim, a brucelose na espécie ovina passou a ter maior importância em cenário nacional para os criadores, com a finalidade de promover um maior controle dela, assim como reduzir as perdas econômicas diante dos problemas reprodutivos que causa.

Entre os métodos sorológicos seguros e mais utilizados atualmente para o diagnóstico da brucelose ovina, tem-se a técnica de imunodifusão em gel de ágar (IDGA), o ensaio imunoenzimático indireto (ELISAi) e a fixação do complemento (Nielsen et al., 2008). O Ministério da Agricultura, Pecuária e Abastecimento recomenda o teste de IDGA como técnica padrão de triagem para o diagnóstico da brucelose ovina (Brasil, 2004).

Assim como as provas sorológicas são requeridas para o diagnóstico da brucelose ovina, as provas moleculares também têm sido amplamente usadas, substituindo o isolamento microbiano, uma vez que a reação em cadeia da polimerase (PCR) é uma prova eficiente, específica, sensível e menos onerosa, contrapondo-se ao isolamento microbiológico, que, apesar de ainda ser o padrão ouro para o diagnóstico direto de animais suspeitos, caracteriza-se por ser um método laborioso e demorado (Bricker, 2002).

Em virtude da importância econômica da espécie ovina, bem como dos prejuízos desencadeados pela infecção por $B$. ovis, objetivou-se a avaliação de três técnicas, sendo duas sorológicas, ELISAi e IDGA, e uma molecular, PCR. Elas foram escolhidas e empregadas objetivando tanto a investigação da situação no que se refere à infecção por $B$. ovis em ovinos naturalmente infectados, oriundos de nove municípios da microrregião de Teresina/Piauí, quanto a aplicabilidade como métodos de diagnóstico.

\section{MATERIAL E MÉTODOS}

A pesquisa foi desenvolvida por meio de levantamento de amostras de sangue de ovinos oriundos de propriedades de nove municípios pertencentes à microrregião homogênea da capital de Teresina, Piauí. Para o uso de animais no experimento, o projeto foi avaliado $\mathrm{e}$ aprovado pela Comissão de Ética e Experimentação no Uso de Animais em Pesquisa, da Universidade Federal do Piauí, sob protocolo $\mathrm{n}^{\circ}$ 030/14.

A pesquisa de anticorpos anti-B. ovis por meio da técnica de IDGA foi realizada no Laboratório de Fisiopatologia da Reprodução da Universidade Federal do Piauí (UFPI), o teste ELISAi e a técnica de PCR foram realizados no Instituto de Ciências Biológicas da Universidade Federal de Minas Gerais (UFMG).

Para a determinação do tamanho da amostra (n), admitiu-se uma prevalência esperada da doença de $20 \%$, um nível de confiança de $95 \%$ e uma variação de $5 \%$. As fórmulas utilizadas foram segundo Thrusfield (2004). Os animais foram incluídos no estudo de forma aleatória, pertenciam a ambos os sexos e apresentavam idade superior a seis meses. Para a determinação da amostragem das propriedades a serem incluídas no estudo, utilizaram-se informações do cadastro de propriedades rurais, produtoras de ovinos, da Agência de Defesa Agropecuária do Estado do Piauí (Adapi), as quais foram incluídas mediante sorteio aleatório.

Foram analisadas 211 amostras de animais da espécie ovina, sem raça definida. Nenhum deles 
foi submetido à inoculação experimental por $B$. ovis, uma vez que se objetivava a detecção de animais naturalmente infectados, por meio das três técnicas aqui descritas.

As amostras para sorologia foram obtidas por venopunção da jugular, utilizando-se tubos de coleta a vácuo de $10 \mathrm{~mL}$ sem anticoagulante. Os tubos contendo as amostras foram mantidos em uma caixa isotérmica contendo gelo para o transporte. $\mathrm{O}$ sangue foi mantido em temperatura ambiente durante uma a duas horas para coagular. Posteriormente foi submetido à centrifugação $2.500 \mathrm{~g}$ por 10 minutos para obtenção dos soros, que foram armazenados a $20^{\circ} \mathrm{C}$.

No teste de IDGA, o antígeno empregado foi produzido pelo Instituto de Tecnologia do Paraná (Tecpar) e consiste de proteínas e lipopolissacarídeos solúveis, extraídos da bactéria B. ovis, amostra Reo 198. A prova foi realizada de acordo com as recomendações do laboratório fornecedor.

O gel de ágar foi preparado utilizando-se $1,0 \mathrm{~g}$ de ágar Noble, $100 \mathrm{~mL}$ de tampão borato $\mathrm{pH} 8,3$; $10 \mathrm{~g}$ de hidróxido de sódio. Em seguida, distribuíram-se 4,5\% do gel em placas de Petri. Após a solidificação, o gel foi perfurado usandose perfurador hexagonal com orifícios de $6 \mathrm{~mm}$ de diâmetro, 2,5mm de distância entre as bordas, contendo um orifício central e outros seis periféricos. Os orifícios foram, então, preenchidos com o antígeno (poço central da roseta), soros controle positivos e soros a testar. As placas foram mantidas em câmara úmida, em temperatura ambiente.

A leitura foi realizada após 24, 48 e 72 horas, utilizando-se sistema de iluminação indireta e fundo escuro. A interpretação foi realizada observando-se a formação de linha de precipitação, entre os soros testes e os soros controle positivos com o antígeno. Os soros testes, cujas linhas de precipitação apresentaram identidade com as linhas formadas pelos soros controle positivos, foram considerados positivos. Os soros testes considerados negativos foram aqueles em que não houve formação de linhas de precipitação ou as linhas formadas não apresentaram identidade com as dos soros controle positivos.
$\mathrm{Na}$ realização do ELISAi, utilizou-se antígeno extraído do extrato de lipopolissacarídeo de $B$. ovis Reo 198, produzido pelo laboratório Tecpar, na diluição 1:200 em tampão carbonatobicarbonato a $0,05 \mathrm{M}, \mathrm{pH} 9,6$. O soro foi diluído 1:100 em PBS-T20, contendo 5\% de leite desnatado, e a reação foi marcada com imunoglobulinas de coelho anti-imunoglobulina de ovino, conjugada à peroxidase (DAKO $\left.{ }^{\circledR}\right)$, diluída a 1:10.000 em PBS-T20. A leitura foi feita em leitora de microplaca, utilizando-se filtro de 490nm de comprimento de luz. Amostras com densidade óptica igual ou superior a 0,408 foram consideradas positivas. Todos os procedimentos do ELISAi foram realizados seguindo descrição de Greve et al. (2011).

Para a coleta de sangue, a ser utilizado na técnica de PCR, utilizaram-se tubos de coleta a vácuo com EDTA. Após a coleta, cada tubo foi invertido levemente, de cinco a oito vezes, para homogeneização adequada. Em seguida, os tubos foram acondicionados em caixas isotérmicas com gelo para o transporte.

A extração de DNA foi realizada utilizando-se aproximadamente $500 \mu \mathrm{L}$ de sangue total, os quais foram submetidos a $500 \mu \mathrm{L}$ de tampão TrisEDTA pH $8,0,50 \mu \mathrm{L}$ de SDS a $10 \%, 10 \mu \mathrm{L}$ de proteinase $\mathrm{K}(20 \mathrm{mg} / \mathrm{mL})$ (Invitrogen, Brasil), $500 \mu \mathrm{L}$ de fenol (GE Healthcare, Brasil), $400 \mu \mathrm{L}$ de fenolclorofórmio (GE Healthcare, Brasil), $300 \mu \mathrm{L}$ de álcool isopropílico e $1000 \mu \mathrm{L}$ de etanol a 70\%, conforme descrição de Matrone et al. (2009) e Xavier et al. (2010). O pellet final foi ressuspendido em $30 \mu \mathrm{L}$ de tampão TE estéril e incubado a $56^{\circ} \mathrm{C}$ por 15 minutos. $\mathrm{O}$ material foi estocado a $-20^{\circ} \mathrm{C}$ até a realização da PCR.

A PCR foi realizada utilizando-se os primers AO503 (sequência senso): 5' GCCTACGCTGAAACTTGCTTTTG-3'; (sequência antissenso) 5'ATCCCCCCATCACCATAACCGAAG-3', $228 \mathrm{pb}$. Em cada reação, com volume final de $25 \mu \mathrm{L}$, utilizaram-se $23 \mu \mathrm{L}$ de mix de PCR comercial (Supermix, Invitrogen, Brasil), $0,5 \mu \mathrm{L}$ de cada inicializador a $25 \mathrm{mM}, 0,25 \mu \mathrm{L}$ de Taq DNA polimerase (Invitrogen, Brasil) e entre 100 e 500ng por reação do DNA extraído. Água Milli-Q estéril foi utilizada como controle negativo, e DNA de colônia pura de $B$. ovis extraído por método de fervura foi utilizado como controle positivo. $\mathrm{Na}$ amplificação do 
DNA, foram empregados os seguintes parâmetros de temperatura e tempo de reação: $95^{\circ} \mathrm{C}$ por cinco minutos, seguidos de 30 ciclos de $95^{\circ} \mathrm{C}$ por um minuto, $57^{\circ} \mathrm{C}$ por um minuto e $72^{\circ} \mathrm{C}$ por um minuto e uma etapa final de extensão a $72^{\circ} \mathrm{C}$ por cinco minutos. A análise do produto amplificado foi realizada em gel de agarose (Invitrogen, São Paulo, Brasil) a 1\%, em cuba horizontal com tampão de corrida Tris-Borato EDTA (TBE) $(50 \mathrm{mM}$ de Tris, $50 \mathrm{mM}$ de ácido bórico, 2,5mM de EDTA, pH 8,0) 1X. As bandas foram comparadas com o padrão de peso molecular e foram consideradas positivas aquelas com peso molecular próximo de $228 \mathrm{bp}$ (Xavier et al., 2010).
Os resultados foram colocados em planilha da Microsoft Office Excel 2013, para se calcular a frequência de animais positivos. A análise de concordância entre os testes foi obtida pela estatística kappa, cujo índice foi calculado utilizando-se o programa Stata/SE 10.0.

\section{RESULTADOS E DISCUSSÂO}

Neste estudo, das 211 amostras submetidas à técnica de IDGA para pesquisa de anticorpos anti-B. ovis, $36 \quad(17 \%)$ responderam positivamente ao teste. $\mathrm{O}$ mesmo número de amostras foi submetido ao teste ELISAi e à PCR. No ELISAi, das 211 amostras, sete $(3,3 \%)$ foram reagentes (Tab. 1).

Tabela 1. Número e frequência de animais positivos nos testes IDGA, ELISAi e PCR no diagnóstico da brucelose ovina, nos municípios estudados

\begin{tabular}{|c|c|c|c|c|}
\hline \multirow{2}{*}{ Município } & \multirow{2}{*}{ Examinados } & \multicolumn{3}{|c|}{ Testes de diagnóstico } \\
\hline & & IDGA $(\%)$ & ELISA i (\%) & PCR (\%) \\
\hline Lagoa Alegre & 45 & 0 & 0 & 0 \\
\hline José de Freitas & 40 & $3(7,5)$ & 0 & 0 \\
\hline Nazária & 22 & $3(13,6)$ & 9 & 0 \\
\hline Dermeval Lobão & 10 & $1(10)$ & 0 & 0 \\
\hline Teresina & 35 & $19(54,3)$ & $4(11,4)$ & 0 \\
\hline Lagoa do Piauí & 09 & 0 & 0 & 0 \\
\hline Coivaras & 20 & $1(5)$ & $1(5)$ & 0 \\
\hline Pau Darco & 10 & $8(80)$ & 0 & 0 \\
\hline Beneditinos & 20 & $1(5)$ & 0 & 0 \\
\hline Total & 211 & $36(17,1)$ & $7(3,3)$ & 0 \\
\hline
\end{tabular}

Legenda: IDGA - imunodifusão em gel de ágar, ELISAi - ensaio imunoenzimático indireto e PCR reação em cadeia da polimerase.

$\mathrm{Na}$ PCR, as 211 amostras foram negativas $(0 \%)$ (Tab. 1), o que sugere que o agente infeccioso estudado, B. ovis, não mais estaria presente no sangue, ou seja, em fase bacterêmica. De acordo com estudos, a fase bacterêmica da doença ocorre por volta dos 60 dias após o período de infecção ou inoculação do agente infeccioso. Sugere-se, ainda, que a quantidade de bactérias na corrente sanguínea seria insignificante ao limite de detecção da técnica aplicada. Além dessas possíveis justificativas, vale ressaltar que há substâncias presentes no sangue que inibem a PCR por restringirem a atividade da DNA polimerase (Xavier, 2009; Dergam, 2016).

Também foi observado que as sete amostras reagentes ao teste ELISAi foram igualmente reagentes ao teste IDGA, contudo este último apresentou um maior número de amostras positivas, totalizando 36 ovinos soropositivos oriundos dos municípios de Dermeval Lobão, Teresina, Lagoa do Piauí, Coivaras, Nazária, Pau Darco, José de Freitas e Beneditinos (Tab. 1). De acordo com os resultados obtidos, observa-se que a brucelose ovina encontra-se distribuída nos municípios estudados, podendo causar prejuízos aos produtores de ovinos da região.

No presente estudo, a concordância entre as técnicas de IDGA $x$ ELISAi foi de apenas $28,59 \%$. Essa baixa concordância observada pode ser devido à baixa sensibilidade do método ELISAi realizado neste estudo, que não foi capaz de detectar 29 dos animais positivos no teste IDGA. A concordância entre as técnicas IDGA x PCR e ELISAi x PCR não foi possível calcular, em decorrência da falta de amostras positivas na técnica de PCR. Entretanto, numericamente, observa-se (Tab. 1) que houve uma elevada discordância entre os métodos sorológicos e a 
PCR, possivelmente em razão da baixa predileção da bactéria pelo sangue circulante, não sendo, portanto, detectada a infecção na PCR.

No trabalho desenvolvido por Nozaki et al. (2004), foram utilizadas 1033 amostras de soro de ovinos oriundos dos municípios da região centro-oeste de SP. Das 1033 amostras submetidas ao teste de IDGA sem 2-ME, 124 $(12,0 \%)$ foram reagentes, ou seja, apresentaram linha de precipitação no gel, contudo 871 $(84,3 \%)$ não foram reagentes ao teste e $38(3,7 \%)$ foram consideradas suspeitas, pois apresentaram formação de linhas de precipitação fraco positivas. Observa-se que a frequência de animais positivos encontrada por Nozaki et al. (2004) foi inferior à encontrada neste estudo 36 $(17,06 \%)$. Entretanto, eles relatam que, em 38 $(3,7 \%)$, não foi possível confirmar a positividade, o que diverge deste estudo, em que não houve amostras apresentando reações fraco positivas para serem consideradas como suspeitas ao teste de IDGA.

Em estudo desenvolvido por Greve et al. (2011), foi realizada a padronização de um teste imunoenzimático indireto utilizando-se um antígeno comercial Reo 198 (Tecpar) e, para verificar o desempenho do antígeno e padronizar a técnica, os autores usaram 90 amostras de animais com histórico clínico e sem histórico clínico de brucelose ovina. Após padronização, submeteram 448 amostras de soro de ovinos ao teste e obtiveram como resultado 11 amostras positivas, contudo essas amostras não foram reagentes ao teste de IDGA, o que diferiu deste estudo, pois as sete amostras positivas no ELISAi foram também positivas ao teste de IDGA.

Segundo Xavier et al. (2010), amostras biológicas de sangue não são indicadas para realização do diagnóstico direto de $B$. ovis, uma vez que, em sua pesquisa, os referidos autores submeteram amostras de sangue à técnica molecular PCR e não houve detecção de $B$. ovis ao longo da infecção de ovinos experimentalmente infectados. No entanto, o diagnóstico de brucelose baseado em PCR vem sendo amplamente utilizado para detecção de Brucella spp. em diferentes amostras biológicas, como sangue, leite, sêmen, urina e em órgãos de animais suspeitos (Romero et al., 1995; Cortez et al., 2001; Manterola et al., 2003; Saunders et al., 2007).

Observou-se, na pesquisa realizada por Costa (2010), que, na técnica de PCR gêneroespecífica, submetendo-se 191 amostras biológicas de sêmen, foi obtida uma positividade de 24,08\%; já na técnica de PCR espécieespecífica utilizando-se as mesmas amostras, obteveram-se $15,18 \%$ de amostras positivas. Esses resultados alcançados em ambas as técnicas de PCR diferem dos resultados obtidos em amostras de sangue, uma vez que não houve amostras reagentes à técnica de PCR neste estudo. Tais resultados ratificam o que foi exposto por Xavier et al. (2010), em sua pesquisa, na qual concluíram que amostras biológicas de sangue não são indicadas para realização de testes diagnósticos diretos de brucelose.

\section{CONCLUSÃO}

Ao se analisarem os resultados deste estudo, conclui-se que o teste IDGA apresentou melhor desempenho na detecção de animais reagentes para brucelose ovina, quando comparado aos outros testes utilizados neste estudo (ELISAi e PCR de sangue), e o percentual de animais positivos nos testes sorológicos sugere que a brucelose ovina apresenta-se amplamente distribuída nas regiões estudadas, podendo gerar perdas econômicas para os produtores.

\section{REFERÊNCIAS}

BRASIL. Ministério da Agricultura, Pecuária e Abastecimento. Portaria $\mathrm{n}^{\mathrm{o}} 102$ de 17 de dezembro de 2004. Dispõe sobre o Plano Nacional de Vigilância e Controle da Epididimite Ovina_Brucella ovis. Diário Oficial da União, Brasília, 17 dez. 2004.

BRICKER, B.J. PCR as a diagnostic tool for brucellosis. Vet. Microbiol., v.90, p.435-446, 2002.

CORTEZ, A.; SCARCELLI, E.; SOARES, R.M. et al. Detection of Brucella DNA from aborted bovine foetus by polymerase chain reaction. Aust. Vet. J., v.79, p.500-501, 2001. 
COSTA, L.F. Avaliação comparativa entre PCR gênero-específica, PCR espécie-específica $e$ nested PCR espécie-específica no diagnóstico da infeç̧ão por Brucella ovis. 2010. 43f. Dissertação (Mestrado em Medicina Veterinária) - Faculdade de Medicina Veterinária e Zootecnia, Universidade Estadual Paulista, São Paulo, SP.

DERGAM, C.G. Condição de uso do eDNA (environmental DNA) no monitoramento de Prochilodus argenteus. 2016. 76f. Dissertação (Mestrado em Genética) - Instituto de Ciências Biológicas, Universidade Federal de Minas Gerais, Belo Horizonte, MG.

GREVE, I.C.; SILVA, M.C.A.; TRINDADE, S. et al. Utilização de um antígeno comercial para o teste ELISA indireto na detecção de anticorpos contra a brucelose ovina. Rev. Acad. Ciênc. Agrár. Ambient., v.9, p.379-386, 2011.

MANTEROLA, L.; TEJERO-GARCES, A.; FICAPAL, A. et al. Evaluation of a PCR test for the diagnosis of Brucella ovis infection in semen samples from rams. Vet. Microbiol., v.92, p.6572, 2003.

MARQUES, A.P.R. Caracterização soroepidemiológica da infecção por vírus Maedi-Visna e Brucella ovis em ovinos no estado de Minas Gerais. 2006. 79f. Dissertação (Mestrado em Medicina Veterinária) - Escola de Veterinária, Universidade Federal de Minas Gerais, Belo Horizonte, MG.

MATRONE, M.; KEID, L.B.; ROCHA, V.C.M. et al. Evaluation of DNA extraction protocols for Brucella abortus PCR detection in aborted fetuses or calves born from cows experimentally infected with strain 2308. Braz. J. Microbiol., v.40, p.480-489, 2009.

NIELSEN, N.; SMITH, P.; YU, W.L. et al. Validation of a second generation competitive enzyme immunoassay (CELISA) for the diagnosis of brucellosis in various species of domestic animals. Vet. Immunol. Immunopathol., v.125, p.246-250, 2008.
NOZAKI, C.N.; MEGID, J.; LIMA, K.C. et al. Comparação das técnicas de imunodifusão em gel de ágar e ELISA no diagnóstico de brucelose ovina em cabanhas da região centro-oeste do Estado de São Paulo. Arq. Inst. Biol., v.71, p.1-5, 2004.

NOZAKI, C.N.; SALGADO, V.R.; LIRA, N.S.C. et al. Adaptação e avaliação da reação em cadeia da polimerase para detecção de Brucella ovis em sêmen, urina e órgãos de carneiros infectados experimentalmente. Arq. Bras. Med. Vet. Zootec., v.63, p.1591-1594, 2011.

PESSEGUEIRO, P.; BARATA, C.; CORREIA, J. Brucelose: uma revisão sistematizada. Med. Int., v.10, p.91-100, 2003.

ROMERO, C.; GAMAZO, C.; PARDO, M.; LÓPEZ-GONI, I. Specific detection of Brucella DNA by PCR. J. Clin. Microbiol., v.33, p.615617, 1995.

SAUNDERS, V.F.; REDDACLIFF, L.A.; BERG, T.; HORNITZKY, M. Multiplex PCR for the detection of Brucella ovis, Actinobacillus seminis and Histophilus somni in ram semen. Aust. Vet. J., v.85, p.72-77, 2007.

SCHLABRITZ-LOUTSEVITCH, N.E.; WHATMORE, A.M.; QUANCE, C.R. et al. A novel Brucella isolate in association with two cases of stillbirth in non-human primates - first report. J. Med. Primatol., v.38, p.70-73, 2009.

THRUSFIELD, M.V. Epidemiologia veterinária. 2.ed. São Paulo: Roca, 2004. 556p.

XAVIER, M.N. Desenvolvimento de PCR espécie-específico para o diagnóstico da infecção por Brucella ovis e avaliação comparativa de métodos sorológicos. 2009. 68f. Dissertação (Mestrado em Ciência Animal) Escola de Veterinária, Universidade Federal de Minas Gerais, Belo Horizonte, MG.

XAVIER, M.N.; SILVA, T.M.A.; COSTA, E.A. et al. Development and evaluation of a speciespecific PCR assay for the detection of Brucella ovis infection in rams. Vet. Microbiol., v.145, p.158-164, 2010. 